\title{
MIR124-2 Pre-miRNA
}

National Cancer Institute

\section{Source}

National Cancer Institute. MIR124-2 Pre-miRNA. NCI Thesaurus. Code C132889.

MIR124-2 pre-miRNA (109 bases) is encoded by the human MIR124-2 gene. This

oligonucleotide may be involved in the regulation of neuronal gene expression. 